\title{
The biochemical and molecular characteristics of Streptococcus equi subsp. zooepidemicus isolated from the genital tract of Thoroughbred mares in Korea
}

\author{
Seong-Kyoon Choi, Seong-Guk Kim ${ }^{1}$, Gil-Jae Cho* \\ College of Verterinary Medicine and Institute of Equine Medicine, Kyungpook National University, Daegu 702-701, Korea \\ ${ }^{1}$ Gyeongbuk Veterinary Service Laboratory, Daegu 702-911, Korea
}

(Received 1 April 2011; revised 22 August 2011; accepted 26 August 2011)

\section{Abstract}

\begin{abstract}
Streptococcus equi subsp. zooepidemicus (S. zooepidemicus) is a pathogen of a variety of infections in horse. We studied biochemical and molecular characteristics of $S$. zooepidemicus isolated from the genital tract of Thoroughbred mares in Korea. Seventy-nine isolates were identified as S. zooepidemicus by biochemical and PCR method from 374 horses. The biochemical characteristics of S. zooepidemicus isolates were positive reaction of lactose and sorbitol. However, S. zooepidemicus isoltes were negative reaction of inulin, mannitol, raffinose, trehalose, aesculin hydrolysis, growth in $6.5 \% \mathrm{NaCl}$ and variable reaction of maltose. Epidemiological investigations of $S$. zooepidemicus isolates were performed by fragment analysis of $S z P$ ( $S$. zooepidemicus protective protein) gene, $C N E$ (collagen binding protein) gene and $I S R$ (16s rRNA intergenic spacer region) gene using ABI Prism 3,130 $\times 1$ Genetic Analyzer System. All isolates were shown single amplification size of 906 bp in $C N E$ gene, but $S z P$ and ISR gene were shown variable patterns of fragment size. The characteristics of $S$. zooepidemicus investigated in this study will be very useful for the prevention of infection and the studies of epidemiologic characteristics of $S$. zooepidemicus, causing the severe economic losses due to reproductive failures.
\end{abstract}

Key words : Thoroughbred horse, Genital tract, Streptococcus equi subsp. zooepidemicus

\section{INTRODUCTION}

Bain (1966) reported that $\beta$-hemolytic Streptoccocus was the most severe pathogen in the first year of infection, so only $40 \%$ of the infected horses could deliver the healthy foals and $35 \%$ of all horses could not achieve the successful pregnancy for 3 years. Furthermore Escherichia coli, coagulase positive Staphylococcus spp, Klebsiella pneumoniae, Pseudomonas aeruginosa, Corynebacterium equi suppurative, and fungal infection were also shown to be severe pathogens which make hard recover. Eliminating such bacteria from genital tract was difficult, and proven hard to be treated in cases. The normal flora inhabiting in the prepuce of horses and the

\footnotetext{
*Corresponding author: Gil-jae Cho, Tel. +82-53-950-5978,

Fax. +82-53-950-5955, E-mail. chogj@knu.ac.kr
}

external genitalia and vaginal vestibulum of mares inhibit the growth of the virulent bacteria (Harkness and Wagner, 1983) Among them, Streptococcus equi subsp. zooepidemicus (S. zooepidemicus) caused $75 \%$ of vaginal infection and most of the septic abortion (Roszel and Freeman, 1988). S. zooepidemicus is often isolated from secondary bacterial infections in horse. It can invade the upper respiratory mucosa and lymph nodes after a viral infection, sometimes mimicking strangles. In susceptible mares, it can cause cervicitis, metritis and placentitis (as an ascending infection from the vagina) resulting in abortion. It is the most common cause of mastitis in horses and has been associated with numerous other infections including wound infections, septicemia in colts, lower airway inflammation in young horses. Lower airway inflammation can occur repeatedly in young horses 
and adversely affect subsequent racing performance (Bain, 1966; Choi et al, 2007).

Thoroughbred and Anglo-Arab horse that were imported from Japan and Australia have been used as racing horse in Korea since 1970s. Since early 1980s, Thoroughbred horse breeding has been produced within country for national qualified horse racing and developed domestic animal industry. Now a day, about 26,000 domestic horses were raised including 10,000 improved breed horses and 16,000 native breed horses. Among them, 2,300 Thoroughbred mares and 70 stallions were raised for breeding and about 1,200 foals were bred every years (Choi et al, 2007). The study of the propagation features related to the improvement in productivity Thoroughbred mares raised within the country has been reported. Cho et al (2007) reported the necropsy and histological characterisitics of fibrinopurulent peritonitis and abdominal abscesses associated with $S$. zooepidemicus in a 1 year old Thoroughbred horses in Jeju. However, there are no report the S. zooepidemicus isolated in the genital tract of horse in Korea. At this point, this research will be the first one based on $S$. zooepidemicus infection clinical patterns and characteristics. In particular, the biochemical and genetic features of $S$. zooepidemicus will help out many other parts of similar researches. Furthermore, it will help not only the horses themselves but also people in horse farm, horse riding club and animal hospitals through $S$. zooepidemicus screening system. Therefore, this study performed the biochemical and molecular characteristics of $S$. zooepidemicus isolated from the genital tract of Thoroughbred mares.

\section{MATERIALS AND METHODS}

\section{Animals}

A total of 374 Thoroughbred horses from equine stud farm and raising farm at Jeju and Jangsu were examined for 3 years from June 2006 to July 2009. Samples were collected from vaginal discharge, uterine washing, aborted fetus and uterine of abortion mare in the fifth month of pregnancy. In this study $79 \mathrm{~S}$. zooepidemicus isolated from 374 Thoroughbred horses (230 healthy horses, 143 clinical endometritis horses and 1 abortion fetus) from Jeju and Jeonbuk region in Republic of Korea were investigated. Culture for isolation of S. zooepidemicus was performed according to previously described techniques (Anzai et al, 2002). The vaginal swabs were taken from clitorial fossa of healthy horses, uterine flushing fluids from clinical endometritis horses only. The swabs were transported in modified Stuart's medium(BD, USA) in a portable fridge. Samples were transported to the laboratory in Liquid Stuart Medium (BD, USA) on ice packs and refrigerated until used (Quinn et al, 1993).

\section{Isolation and identification of $\mathcal{S}$. zooepide- micus}

Culture for isolation of $S$. zooepidemicus from samples was performed according to previously described techniques (Widders et al, 1984; Bannerman et al, 2003). Following vortexing of swabs in the sample buffer, the swabs were transferred using sterile technique to individual tubes containing $2 \mathrm{ml}$ of Bacto Todd-Hewitt broth (BD, USA), and incubated in ambient air at $37^{\circ} \mathrm{C}$ overnight. Approximately $10 \mu \mathrm{l}$ of broth was then inoculated on Bloods agar at $37^{\circ} \mathrm{C}$ for 24 h. S. zooepidemicus suspected strains were stored at $-70^{\circ} \mathrm{C}$ in freezer vials containing $15 \%$ sterile glycerol for further analysis. The isolates were identified on the basis of colonial and cellular morphology, gram staining, catalase test, oxidase test, OF-test, and were also identified with VITEK 2 instrument (BioMerieux, France) with Gram Positive (GP) identification card (Eigner et al, 2005).

Identification of $S$. zooepidemicus was performed by using multiplex-PCR with $S$. zooepidemicus suspected strains obtained from biochemistry test. Molecular identification of $S$. zooepidemicus isolates was performed by using sodA-seeI specific multiplex PCR using following primer pairs (Anzai et al, 2002): SodA-F (5'- CAG CAT TCC TGC TGA CAT TCG TCA GG-3') and SodA-R (5'- CTG ACC AGC CTT ATT CAC AAC CAG CC-3'); SeeI-F (5'- GAA GGT CCG CCA TTT TCA GGT ACT TTG-3') and SeeI-R (5'- GCA TAC TCT CTC TGT CAC CAT GTC CTG-3'). The species identification of $S$. zooepidemicus was confirmed by sodA-seeI multiplex 
Table 1. Oligonucleotide primers and PCR programs used for fragment analysis in this study

\begin{tabular}{clcc}
\hline Target gene & \multicolumn{1}{c}{ Sequence $\left(5^{\prime} \rightarrow 3^{\prime}\right), 5^{\prime}$-Fluorescent label } & PCR program & Size of product \\
\hline \multicolumn{1}{c}{$C N E$} & F-(6-FAM $*$ GCAACTAATCTTAGTGACAACAT & $1^{\dagger}$ & $906 \mathrm{bp}$ \\
& R-AAAGCTGGTATAGCGACTGCCA & & Size polymorphism \\
$I S R$ & F-(6-FAM)TTGTACACACCGCCCGTCA & $2^{\ddagger}$ & Size polymorphism \\
& R-GGTACCTTAGATGTTTCAGTT $P$ & F-(6-FAM)ACAAAAGGGGAATAAAATGGC & $3^{\S}$ \\
& R-TTTACCACTGGGGTATAAGGCT & & \\
\hline
\end{tabular}

${ }^{*}$ Carboxyfluorescein, ${ }^{\dagger} 1 \times\left(95^{\circ} \mathrm{C} 180 \mathrm{~s}\right), 20 \times\left(94^{\circ} \mathrm{C} 30 \mathrm{~s}, 54^{\circ} \mathrm{C} 40 \mathrm{~s}, 72^{\circ} \mathrm{C} 50 \mathrm{~s}\right), 1 \times\left(72^{\circ} \mathrm{C} 180 \mathrm{~s}\right),{ }^{\ddagger} 1 \times\left(95^{\circ} \mathrm{C} 180 \mathrm{~s}\right), 20 \times\left(94^{\circ} \mathrm{C} 60 \mathrm{~s}, 58^{\circ} \mathrm{C} 60 \mathrm{~s}, 72^{\circ} \mathrm{C}\right.$ $60 \mathrm{~s}), 1 \times\left(72^{\circ} \mathrm{C} 180 \mathrm{~s}\right),{ }^{8} 1 \times\left(95^{\circ} \mathrm{C} 180 \mathrm{~s}\right), 20 \times\left(94^{\circ} \mathrm{C} 30 \mathrm{~s}, 50^{\circ} \mathrm{C} 60 \mathrm{~s}, 72^{\circ} \mathrm{C} 90 \mathrm{~s}\right), 1 \times\left(72^{\circ} \mathrm{C} 180 \mathrm{~s}\right)$.

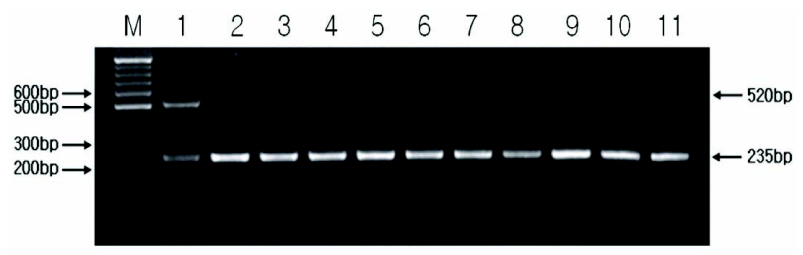

Fig. 1. PCR amplification of sodA-seeI for identifi-cation of $S$. zooepidemicus. Lane M: molecular size marker (100 bp DNA ladder, Elpis, Korea), lane 1: $S$. equi isolates, lane 2 to 11: S. zooepidemicus isolates. S. zooepidemicus were identified by PCR products of only $235 \mathrm{bp}$ in the $S o d A$ gene. as it was compared with PCR products of both $235 \mathrm{bp}$ and $520 \mathrm{bp}$ in S. equi.

PCR giving a positive sodA gene (235 bp) and negative seeI gene (520 bp) reaction. PCR assays were accomplished in a total volume of $25 \mu \mathrm{l}$ of the following mixtures: $2 \mu \mathrm{l}$ DNA, $2 \mu \mathrm{l}(10 \mathrm{pmol} / \mu \mathrm{l})$ of each primer, 12.5 $\mu \mathrm{l}$ of $10 \times$ reaction buffer (Qiagen, Germany), and $6.5 \mu \mathrm{l}$ distilled water. PCR amplification was as follows: first step was performed by initial denaturation for $3 \mathrm{~min}$ at $94^{\circ} \mathrm{C}$, followed by 30 cycles at $94^{\circ} \mathrm{C}$ for $30 \mathrm{sec}, 59^{\circ} \mathrm{C}$ for $30 \mathrm{sec}$ and $72^{\circ} \mathrm{C}$ for $40 \mathrm{sec}$ for sodA-seel. After identification, bacteria were stored at $-70^{\circ} \mathrm{C}$ until use (Bannerman et al, 2003; Bienert et al, 2003).

\section{Fragment analysis of $S$. zooepidemicus}

PCR amplification (Hirota et al, 2010) was performed in a reaction mixture of $10 \mu \mathrm{l}$ containing $5 \mu \mathrm{l}$ of Multiplex Master Mix (Qiagen, Germany), 30 ng of DNA template, and $S z P(S$. zooepidemicus protective protein) gene, CNE (collagen binding protein) gene and ISR (16s rRNA intergenic spacer region) specific primers, respectively (Younan et al, 2005). Concentration, primer sequences, PCR programme and respective dyes used are shown in the Table 1. PCRs were performed and prepared for subsequent analysis on sequencers in accordance with the manufacturer's instructions. Amplification products were diluted 1:10 with water purified by high performance liquid chromatography, and $0.5 \mu \mathrm{l}$ of diluted DNA was mixed with $9.5 \mu \mathrm{l}$ of Hi-Di formamide (Applied Biosystems, USA) and $0.5 \mu \mathrm{l}$ of GeneScan-1200 LIZ Size Standard (Applied Biosystems, USA) as internal lane size standard. Before fragment sizing in ABI Prism 3,130 xl Genetic Analyzer System (Applied Biosystems, USA), samples were incubated for 2 min at $95^{\circ} \mathrm{C}$ and immediately frozen at $20^{\circ} \mathrm{C}$ for $>3$ min to denature the DNA. If a $S z P$ and $I S R$ were not detected during fragment analysis, reactions were repeated by using singleplex reactions with minor modifications to amplify the specific locus. In that particular instance, the primer concentration was increased to 0.2 $\mu$ mole $/ \mathrm{ml}$, annealing temperatures were reduced to $49^{\circ} \mathrm{C}$, and the extension time was tripled to amplify larger fragments because of possible insertion sequence element transposition or other genetic events (Lee and Cho, 2006; Lindstedt et al, 2007; Hirota et al, 2010; HyytiaTrees et al, 2010). After fragment analysis, corresponding peak data were examined by using GeneMapper Ver. 4.0 software (Applied Biosystems, USA).

\section{RESULTS}

\section{Isolation and identification of $\mathcal{S}$. zooepide- micus}

Seventy-nine of S. zooepidemicus isolates from 374 samples in this study grew as small, grey to white colo- 
Table 2. The isolation frequency of S. zooepidemicus isolates isolated from Thoroughbred horses

\begin{tabular}{lccc}
\hline \multirow{2}{*}{ Specimen } & \multicolumn{2}{c}{ No. of positive/test samples (\%) } & Total \\
\cline { 2 - 3 } & \multicolumn{1}{c}{ Jeju } & Jangsu & $1 / 1(100)$ \\
\hline Aborted fetus & $1 / 1(100)$ & - & $1 / 1(100)$ \\
Uterine of abortion mare & $1 / 1(100)$ & - & $20 / 230(8.7)$ \\
Healthy horse (Vaginal discharge) & $16 / 82(19.5)$ & $4 / 148(2.7)$ & $57 / 142(40.1)$ \\
Endometritis (Uterine washing) & $42 / 102(41.8)$ & $15 / 40(37.5)$ & $79 / 374(21.2)$ \\
Total & $60 / 186(32.3)$ & $19 / 188(10.1)$ & \\
\hline
\end{tabular}

Table 3. Biochemical characteristics of 79 S. zooepidemicus

\begin{tabular}{lclc}
\hline \multicolumn{1}{c}{ Substrates } & No. of positive isolates (\%) & \multicolumn{1}{c}{ Substrates } & No. of positive isolates (\%) \\
\hline D-amygdalin & $0(0.0)$ & Lactose & $76(96.2)$ \\
Ala-Phe-Pro arylamidase & $79(100.0)$ & D-mannitol & $52(65.8)$ \\
Leucine arylamidase & $79(100.0)$ & Salicin & $71(89.9)$ \\
Alanine arylamidase & $79(100.0)$ & Urease & $0(0.0)$ \\
D-ribose & $16(20.3)$ & D-mannose & $79(100.0)$ \\
Novobiocin resistance & $67(84.8)$ & Saccharose/sucrose & $72(91.1)$ \\
D-raffinose & $0(0.0)$ & Beta galactopyranosidase & $29(36.7)$ \\
Optochin resistance & $79(100.0)$ & Alpha mannosidase & $0(0.0)$ \\
Cyclodextrin & $58(73.4)$ & Polymixin b resistance & $56(70.9)$ \\
L-proline arylamidase & $3(3.8)$ & D-maltose & $79(100.0)$ \\
Tyrosine arylamidase & $79(100.0)$ & D-trehalose & $0(0.0)$ \\
L-lactate alkalinization & $0(0.0)$ & Alpha glucosidase & $79(100.0)$ \\
Growth in 6.5\% NaCl & $0(0.0)$ & Phosphatase & $79(100.0)$ \\
D-xylose & $0(0.0)$ & D-galactose & $79(100.0)$ \\
Beta glucuronidase & $31(39.2)$ & Bacitracin resistance & $53(67.1)$ \\
D-sorbitol & $13(16.5)$ & Pullulan & $79(100.0)$ \\
\hline
\end{tabular}

nies on 5\% sheep blood agar plates surrounded by a wide zone of complete hemolysis. S. zooepidemicus species-specific sodA-seeI gene generated by 235 bp fragments (Fig. 1). It was isolated 60 (32.3\%) samples from Jeju and 19 (10.1\%) from Jangsu, respectively (Table 2). $S$. zooepidemicus isolates was isolated from uterine washing fluid (40.1\%) and vaginal discharge (8.7\%).

\section{Biochemical characteristics of $S$. zooepide- micus}

The biochemical characteristics of $S$. zooepidemicus isolates are shown in Table 3. The S. zooepidemicus isolates were showed Gram positive cocci that occur in pairs, facultative anaerobes, catalase-negative, oxidasenegative, non- motile. A total of 79 isolates shown the same pattern in the majority of biochemical properties such as Ala-Phe-Pro arylamidase (100.00\%), Leucine arylamidase $(100.00 \%)$, Alanine arylamidase $(100.00 \%)$,
Optochin resistance $(100.00 \%)$, Tyrosine arylamidase (100.00\%), D-mannose (100.00\%), Alpha glucosidase (100.00\%), D-maltose (100.00\%), D-galactose (100.00\%), Phosphatase (100.00\%). But, D-ribose (20.3\%), Cyclodextrin (73.4\%), Beta glucuronidase (39.2\%), D-sorbitol (16.5\%), Lactose (96.2\%), D-mannitol (65.8\%), Salicin $(89.9 \%)$ showed the diversity by isolates.

\section{Molecular characteristics of $S$. zooepidemicus}

Fragment analysis of $S$. zooepidemicus isolates is shown in Fig. $2 \sim 4$. All isolates were shown single amplification size of $906 \mathrm{bp}$ in $C N E$ gene, but $S z P$ gene was shown variable patterns, $1,158 \mathrm{bp}(\mathrm{n}=2)$ and 1,118 bp $(\mathrm{n}=77)$. Fragment size of ISR gene were observed 769 bp $(\mathrm{n}=33), 783$ bp $(\mathrm{n}=4), 787$ bp $(\mathrm{n}=25), 933$ bp $n=3), 940$ bp $(n=10), 953$ bp $(n=3)$, and 1,074 bp $(n=1)$. 


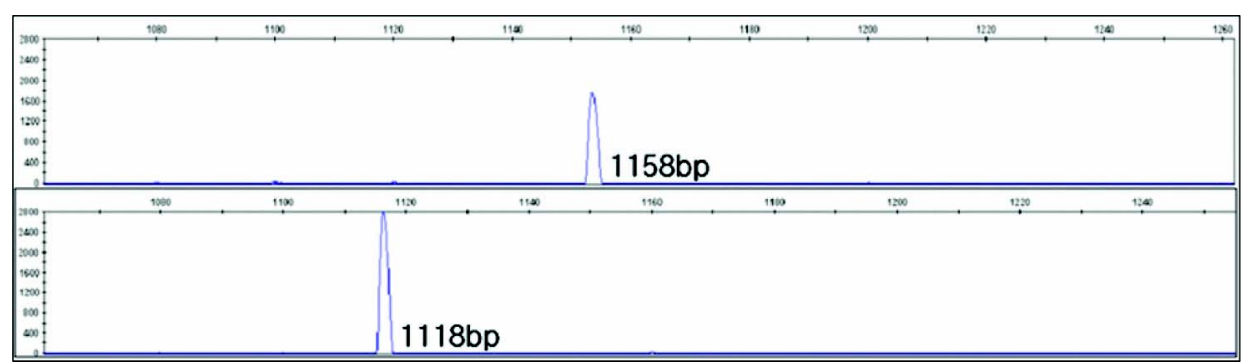

Fig. 2. Peak data of $S z P$ fragment analysis. After fragment analysis, $S z P$ peak data were examined by using GeneMapper Ver. 4.0 software (Applied Bio-systems, USA). S. zooepidemicus isolates with sizes of $1,158 \mathrm{bp}, 1,118 \mathrm{bp}$.

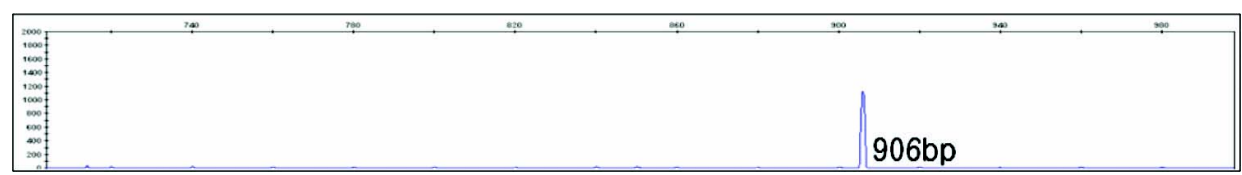

Fig. 3. Peak data of $C N E$ fragment analysis. After fragment analysis, $C N E$ peak data were examined by using GeneMapper Ver. 4.0 software (Applied Bio- systems, USA). S. zooepidemicus isolates with sizes of $906 \mathrm{bp}$.

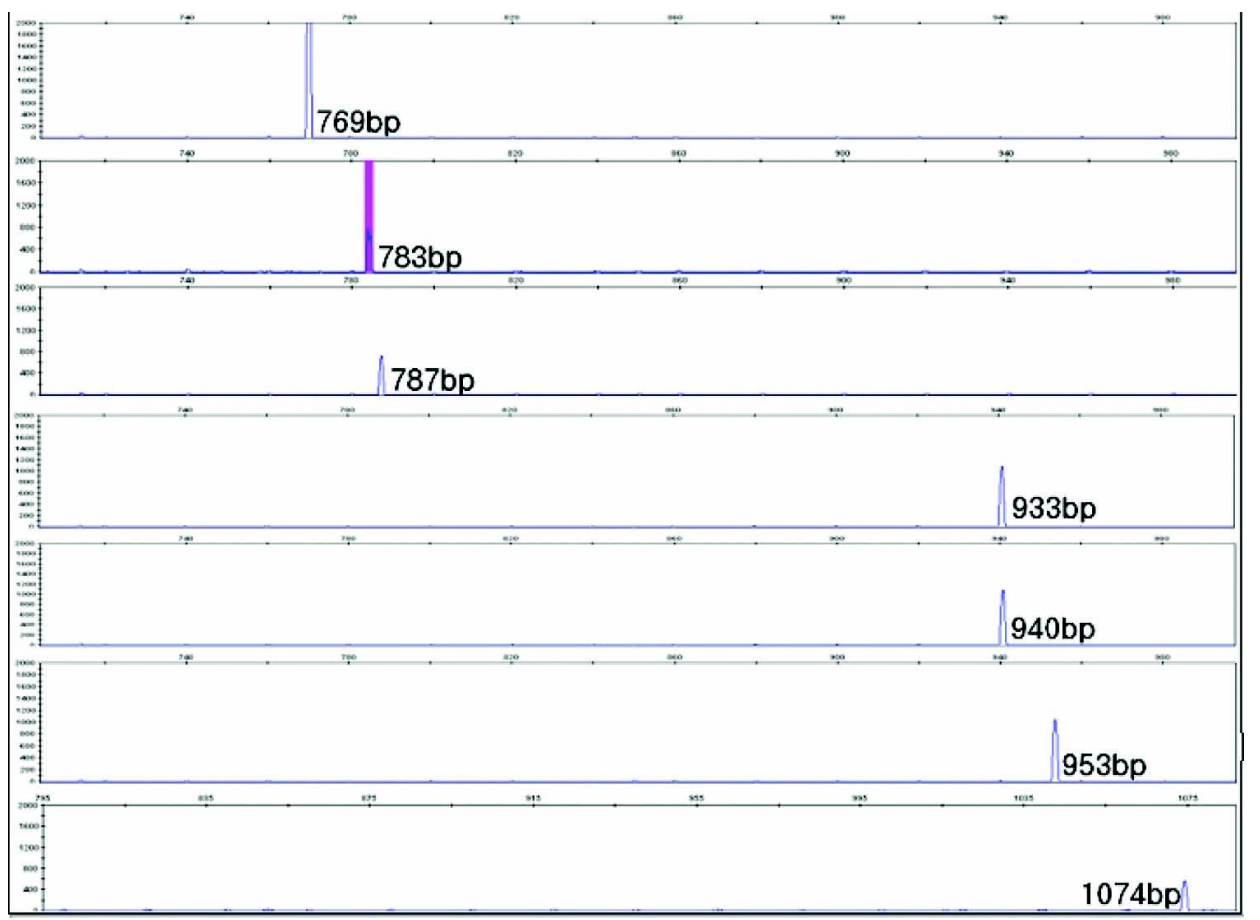

Fig. 4. Peak data of $I S R$ fragment analysis. After fragment analysis, ISR peak data were examined by using GeneMapper Ver. 4.0 software (Applied Bio- systems, USA). S. zooepidemicus isolates with sizes of $769 \mathrm{bp}$, 783 bp, 787 bp, 933 bp, 940 bp, 953 bp, 1,074 bp.

\section{DISCUSSION}

Genital infections are a significant source of reproductive failure and economic loss to the horse breeding industry (Jeffcott et al, 1982; Pycock and Allen, 1990; Miragaya et al, 1997; Ozgur et al, 2001). The principal cause of endometritis in mare is S. zooepidemicus, the isolation rate of which range from 22 to $54 \%$ of affected mares (Bain, 1966; Asbury et al, 1980; Wingfield Digby and Ricketts, 1982; Widders et al, 1985). S. zooepidemicus has also been identified as the primary etiological agent in 15 to $20 \%$ of equine abortions (Rober, 1971; Widders et al, 1984).

Frontoso et al (2008) reported that samples were collected from the uterine of 75 mares and tested with rectal palpation and ultrasonography for foal heat. As a re- 
sult of the bacterial test from the samples, 49 horses $(65.3 \%)$ in total showed positive reaction and beta hemolytic Streptococcus $(25.3 \%)$ and E. coli $(24.0 \%)$ were the most frequently detected bacteria. It is primarily required not only to select the horses being of good line, but also to establish and improve the technique of horse breeding in order to meet the needs of Korean horse market and secure nicer race horses and riding horses.

The samples in this study were collected from Jangsu and Jeju. But the selection for sampling done intensively from the certain regions including Jangsu and Jeju is attributed to the geographical nature peculiar to horse raising and reproducing. As to the domestic horse breeding, more than $95 \%$ is confined to Jeju and Jangsu. With this condition considered, it is preferred that other types of diseases be examined at the same time as well as the survey over S. zooepidemicus infection rate. The isolation rate of $\mathrm{S}$. zooepidemicus in this study was indicated comparatively higher than that of Bain with $22 \%$ (Bain, 1966) and lower than those like Welsh with $54 \%$ (Welsh, 1984). It is a reality that there has not been any survey practically about S. zooepidemicus infection rate in the country. It is hard to mention any other studies available and simple comparison. However, the comparatively high rate of $\mathrm{S}$. zooepidemicus in this study is sure to appear domestically when compared to such foreign case study by Roszel and Freeman (1988) and McKinnon and Voss (1993).

Although there were some differences in sorbitol, lac-

Table 4. Molecular characteristics of 79 S. zooepidemicus

\begin{tabular}{lcccc}
\hline \multirow{2}{*}{ Gene } & \multirow{2}{*}{$\begin{array}{c}\text { Fragment } \\
\text { size }\end{array}$} & \multicolumn{2}{c}{ Region } & Toju (\%) \\
\cline { 3 - 4 } & & Jangsu (\%) & \\
\hline CNE & $906 \mathrm{bp}$ & $60^{*} / 60^{\dagger}(100)$ & $19 / 19(100)$ & $79 / 79(100)$ \\
$S z P$ & $1,118 \mathrm{bp}$ & $58 / 60(96.7)$ & $19 / 19(100)$ & $77 / 79(100)$ \\
& $1,158 \mathrm{bp}$ & $2 / 60(3.3)$ & - & $2 / 79(100)$ \\
$I S R$ & $769 \mathrm{bp}$ & $30 / 60(50.0)$ & $3 / 19(15.8)$ & $33 / 79(41.8)$ \\
& $783 \mathrm{bp}$ & $4 / 60(6.7)$ & - & $4 / 79(5.1)$ \\
& $787 \mathrm{bp}$ & $20 / 60(33.3)$ & $5 / 19(26.3)$ & $25 / 79(31.6)$ \\
& $933 \mathrm{bp}$ & - & $3(15.8)$ & $3 / 79(3.8)$ \\
& $940 \mathrm{bp}$ & $6 / 60(10.0)$ & $4 / 19(21.1)$ & $10 / 79(12.7)$ \\
& $953 \mathrm{bp}$ & - & $3(15.8)$ & $3 / 79(3.8)$ \\
& $1,074 \mathrm{bp}$ & - & $1(5.5)$ & $1 / 79(1.3)$ \\
\hline
\end{tabular}

*No. of positive, ${ }^{\dagger}$ Test samples (\%). tose, salicin, maltose among $79 \mathrm{~S}$. zooepidemicus tested in this study, the results obtained were almost in accordance with the traditionally biochemical characteristics of $S$. zooepidemicus isolates. Interestingly, our results showed that the fermentation rate for sorbitol $(16.46 \%)$ in this study was indicated comparatively lower than traditionally biochemical characteristics of $S$. zooepidemicus (Quinn et al, 1993). As a result of fragment analysis about $C N E$, it was confirmed that all Korean isolates were of same amplification size due to the observation of amplification size of $906 \mathrm{bp}$ in all isolated strains.

However, analyzing epidemiological properties and characteristics of strains using $C N E$ fragment analysis was difficult. But in the case of $S z P$ virulence factors, 1,158 bp $(\mathrm{n}=2), 1,118 \mathrm{bp}(\mathrm{n}=77)$ and ISR gene region, 769 bp (n=33), 783 bp $(n=4), 787$ bp $(n=25), 933$ bp $(\mathrm{n}=3), 940$ bp $(\mathrm{n}=10), 953$ bp $(\mathrm{n}=3), 1,074$ bp $(\mathrm{n}=1)$ amplicon size observed. Based on fragment analysis of $\mathrm{SzP}$ results, we observed that most of the 60 strains isolated from Jeju had amplification sizes of $1,158 \mathrm{bp}(\mathrm{n}=2)$, $1,118 \mathrm{bp}(\mathrm{n}=58)$ and the 19 strains isolated from Jangsu had amplification size of $1,118 \mathrm{bp}(\mathrm{n}=19)$. Isolates from Jeju were classified into two groups, while those of Jangsu were categorized into one group by fragment analysis results of $S z P$ gene.

Also, based on fragment analysis of ISR results, we observed that most of the $60 \mathrm{~S}$. zooepidemicus strains isolated from Jeju had amplification sizes of $769 \mathrm{bp}$ $(\mathrm{n}=30), 783 \mathrm{bp}(\mathrm{n}=4), 787 \mathrm{bp}(\mathrm{n}=20), 940 \mathrm{bp}(\mathrm{n}=6)$ and the $19 \mathrm{~S}$. zooepidemicus strains isolated from Jangsu had amplification sizes of 769 bp $(n=3), 787 \mathrm{bp}(\mathrm{n}=5)$, 933 bp $(n=3), 940$ bp $(n=4), 953$ bp $(n=3), 1,074$ bp $(\mathrm{n}=1)$ (Table 4). S. zooepidemicus strains isolated from Jeju were classified into five groups, while those of Jangsu were categorized into six groups by fragment analysis of $I S R$ gene.

It is difficult to confirm the characteristics of isolates from each area merely based on $S z P$ and $I S R$ fragment analysis. But, it is highly correlated with the fact that various $S z P$ and $I S R$ patterns were shown in Jeju and Jangsu. These results indicate a high genetic heterogeneity among the isolates which would be related either with the wide distribution of this microorganism in equine population, or with the fact that $S$. zooepidemicus 
strains were isolated from individual mares, most of them belonging to single owners without any epidemiological or geographical relationship between them and possibility of influx of diseases from other areas.

\section{ACKNOWLEDGMENTS}

This study was supported by the Technology Development Program for Agriculture and Forestry (10817503-1-CG000), Ministry for Agriculture, Forestry and Fisheries, Republic of Korea.

\section{REFERENCES}

Anzai T, Timoney JF, Kuwamoto T, Wada R, Oikawa M, Higuchi T. 2002. Polymerase chain reaction restriction fragment length polymorphism analysis of the $S z P$ gene of Streptococcus zooepidemicus isolated from the respiratory tract of horses. Am J Vet Res 63: 1298-1301.

Asbury AC, Halliwell RE, Foster GW, Longino SJ. 1980. Immunoglobulin in uterine secretion of mares with differing resistance to endometritis. Therigenology 14: 299-308.

Bain AM. 1966. The role of infection in infertility in the thoroughbred mare. Vet Rec 78: 168-173.

Bannerman DD, Paape MJ, Hare WR, Sohn EJ. 2003. Increased levels of LPS-binding protein in bovine blood and milk following bacterial lipopolysaccharide challenge. J Dairy Sci 86: 3128-3137.

Bienert A, Bartmann CP, Verspohl J, Deegen E. 2003. Bacteriological findings for endodontical and apical molar dental diseases in the horse. Dtsch Tierarztl Wochenschr 110: 358-361.

Cho JJ, Kang SC, Yang HS, Yang JH, Son, WG, Bae JH, Kim JH, 2007. Peritonitis associated with Streptococcus equi subsp. zooepidemicus in a thoroughbred horse. Korean J Vet Res 47: 315-319.

Choi SK, Lee SG, Yang JH, Cho GJ. 2007. Distribution and antimicrobial susceptibility patterns of bacteria isolated from genital tract in Thoroughbred mares. J Vet Clin 24: 19-25.

Eigner U, Schmid A, Wild U, Bertsch D, Fahr AM. 2005. Analysis of the comparative workflow and performance characteristics of the VITEK 2 and Phoenix systems. J Clin Microbiol 43: 3829-3834.

Frontoso R, De Carlo E, Pasolini MP, van der Meulen K, Pagnini U, Iovane G, De Martino L. 2008. Retrospective study of bacterial isolates and their antimicrobial susceptibilities in equine uterine during fertility problems. Res
Vet Sci 84: 1-6.

Harkness JE, Wagner JE. 1983. The biology and medicine of rabbits and rodents. 2nd ed. pp. 173-175. Lea and Febiger, Philadelphia.

Hirota KI, Kakoi H, Gawahara H, Hasegawa T, Tozaki T. 2010. Construction and validation of parentage testing for thoroughbred horses by 53 single nucleotide polymorphisms. J Vet Med Sci 72: 719-726.

Hyytia-Trees E, Lafon P, Vauterin P, Ribot EM. 2010. Multilaboratory validation study of standardized multiple-locus variable-number tandem repeat analysis protocol for shiga toxin-producing Escherichia coli O157: a novel approach to normalize fragment size data between capillary electrophoresis platforms. Foodborne Pathog Dis 7: 129-136.

Jeffcott LB, Rossdale PD, Freestone J, Frank CJ, Towers-Clark PF. 1982. An assessment of wastage in thoroughbred racing from conception to 4 years of age. Equine Vet $\mathrm{J}$ 14:185-198.

Lee SY, Cho GJ. 2006. Parentage testing of Thoroughbred horse in Korea using microsatellite DNA typing. J Vet Sci 7: 63-67.

Lindstedt BA, Torpdahl M, Nielsen EM, Vardund T, Aas L, Kapperud G. 2007. Harmonization of the multiple-locus variable-number tandem repeat analysis method between Denmark and Norway for typing Salmonella Typhimurium isolates and closer examination of the VNTR loci. J Appl Microbiol 102: 728-735.

McKinnon AO, Voss JL, 1993. Equine reproduction. pp. 246-253. Lea \& Rebiger, Philadephia.

Miragaya MH, Woods GL, Losinno L. 1997. Endometritis, salpingitis and fertilisation rates after mating mares with a history of intrauterine lumenal fluid accumulation. Equine Vet J Suppl 25: 109-112.

Ozgur NY, Ikiz S, Carioglu B, Kilicarslan R, Yilmaz H, Akay O, Ilgaz A. 2001. Contagious equine metritis in Turkey: first isolation of Taylorella equigenitalis from mares. Vet Rec 149: 120-122.

Pycock JF, Allen WE. 1990. Inflammatory components in uterine fluid from mares with experimentally induced bacterial endometritis. Equine Vet J 22: 422-425.

Quinn PJ, Carter ME, Markey B, Carter GR. 1993. Clinical Veterinary Microbiology. 9th ed. pp. 127-136. Mosby, London.

Rober SJ. 1971. Veterinary obstetrics and genital disease. 2nd ed. pp. 135-136. Theriogenology Edward bros.

Roszel JF, Freeman KP. 1988. Equine endometrial cytology. Vet Clin North Am Equine Pract 4: 247-262.

Welsh RD. 1984. The siginificance of Streptococcus zooepidemicus in the horse. Equine practice 6: 6-16.

Widders PR, Stokes CR, David JS, Bourne FJ. 1984. Quantitation of the immunoglobulins in reproductive tract secretions of the mare. Res Vet Sci 37: 324-330.

Widders PR, Stokes CR, David JS, Bourne FJ. 1985. Effect of cycle stage on immunoglobulin concentrations in reproductive tract secretions of the mare. J Reprod Immu- 
nol 7: 233-242.

Wingfield Digby NJ, Ricketts SW. 1982. Results of concurrent bacteriological and cytological examinations of the endometrium of mares in routine stud farm practice 19781981. J Reprod Fertil Suppl 32: 181-185.

Younan M, Estoepangestie AT, Cengiz M, Alber J, El-Sayed A,
Lämmler C. 2005. Identification and molecular characterization of Streptococcus equi subsp. zooepidemicus isolated from camels (Camelus dromedarius) and camel milk in Kenya and Somalia. J Vet Med B Infect Dis Vet Public Health 52: 142-146. 